\title{
Optimal Pipelines Sizing for Distribution Systems with Draw-off Stations
}

\author{
HABEEBULLAH, M. B. AND ZAKI, G. M. \\ College of Engineering, King Abdulaziz University \\ P.O. Box 9027, Jeddah 21413, Saudi Arabia
}

\begin{abstract}
The present study focuses on developing a cost function for pump-pipelines system with emitters randomly distributed along the pipelines. The objective function is based on the capital cost of the piping system, pumps and the cost of energy required to operate the system. Employing the least annual cost principle to obtain the optimal diameter of each pipe leads to a nonlinear system of equations. A solution procedure based on an iterative scheme is proposed and examined for three case studies. The first case is a three-parallel pipeline system with 12 emitters. The second case is a two-pipeline system of the actual irrigation network at King Abdulaziz University Campus, with 26 emitters. A single pipeline $5.8-\mathrm{km}$ long with three draw-off points is the third case study.
\end{abstract}

\section{Introduction}

The selection of a pipeline size to meet a specific criterion, such as the minimum annual expenses, has been extensively treated by Nolte ${ }^{[1]}$. For the least annual cost (LAC) as the selection criteria the length of the pipeline does not effect the optimum pipe diameter. The analysis could be performed only for a unit length. This result is important for pipelines transporting fluids between two fixed stations without any fluid extraction or inflow in-between. Hathoot ${ }^{[2]}$ reconsidered the single pipeline optimization problem with several boosting pumps at equal distances. Analytical expressions were obtained for the minimum annual cost and optimum pipe diameter. Ferreira and Vidal ${ }^{[3]}$ extended the conditions of Hathoot ${ }^{[2]}$ to include the distance between boosting stations and the 
pipeline wall thickness as decision parameters. An economic analysis of the pump-pipeline system was presented by Kabir ${ }^{[4]}$, which was oriented to sensitivity analysis of the annual cost to variations in interest rate, bonds issue and construction cost.

The use of multi-criterion optimization methods for pipe network analysis has been reviewed by Stephenson ${ }^{[5]}$. This extensive study showed that the dynamic programming schemes are suitable for pipe size selection of main and trunk pipelines. Transportation programming is convenient for cases in which the pipe routes and size are to be optimally selected. Because of the complex network analysis a special network linear programming (NWLP) algorithm has been developed. Comparison between the NWLP and the ordinary linear programming routines, Kuczera ${ }^{[6]}$ showed that the NWLP method requires less time as compared to the LP algorithms. With the advances in optimization search methods, network analysis has been extended beyond the classical problem of selecting size of pipes, pumps and routes (Cembrowicz et al ${ }^{[7]}$ ) to include parameters of different interest. Management of irrigation systems (Srinivasan and Guimaraes ${ }^{[8]}$, Eduardo and Marino ${ }^{[9]}$ and Mohtar et $a l^{[10]}$ ) where the effects of land topography, irrigation method and land allocation is included. Maximization of land yield, profit and/or management of wastewater reuse (Afshar and Miguel ${ }^{[11]}$ ) are just other examples. Application of the genetic algorithms for pipe network optimization is in progress where it may provide some advantages over the classical linear, dynamic and/or nonlinear programming methods (Dandy et al ${ }^{[12]}$ and Simpson et al ${ }^{[13]}$ ).

The present work is directed to the study of pump-branching pipes distribution system with arbitrary located draw-off stations for optimum selection of the pipes diameters on the basis of minimum cost function.

\section{Mathematical Model}

The system considered is a single pumping station with a system of $n$ parallel pipelines. Each of the pipelines, $i$, has a number of emitters $m_{i}$, Fig.1. The emitters may be spaced at equal distances as the case of irrigation lateral system. However, for generality of the analysis the emitters are randomly spaced at $l_{i l}, l_{i 2}, \ldots, l_{i j}, \ldots, l_{i m}$. The flow rate through any pipeline, $i$, is $Q_{i}$, which is distributed at the draw-off or extraction stations $(i, j)$ at a certain ratios $X_{i j}$ of the branch flow rate. Apply the mass conservation principle, assuming constant fluid density, gives the total flow rate entering the system as: 


$$
Q_{t}=\sum_{i=1}^{n} \sum_{j=1}^{m_{i}} X_{i j} Q_{i}
$$

where $X_{i j}$ is the fraction of flow rate drawn off at emitter $i j$. The diameter of a pipeline segment between two emitters $i, j$ and $i, j+1$ (denoted by $D_{i j}$ ) represents one of the control parameters that affect the cost of the system. The second control variable is the cost of energy required to achieve the operation conditions. The cost of energy is a function of the size of the pump and the operation time of the system. The total annual cost (TAC) presents the objective function to be minimized, and is determined from fixed and operation costs in the following:

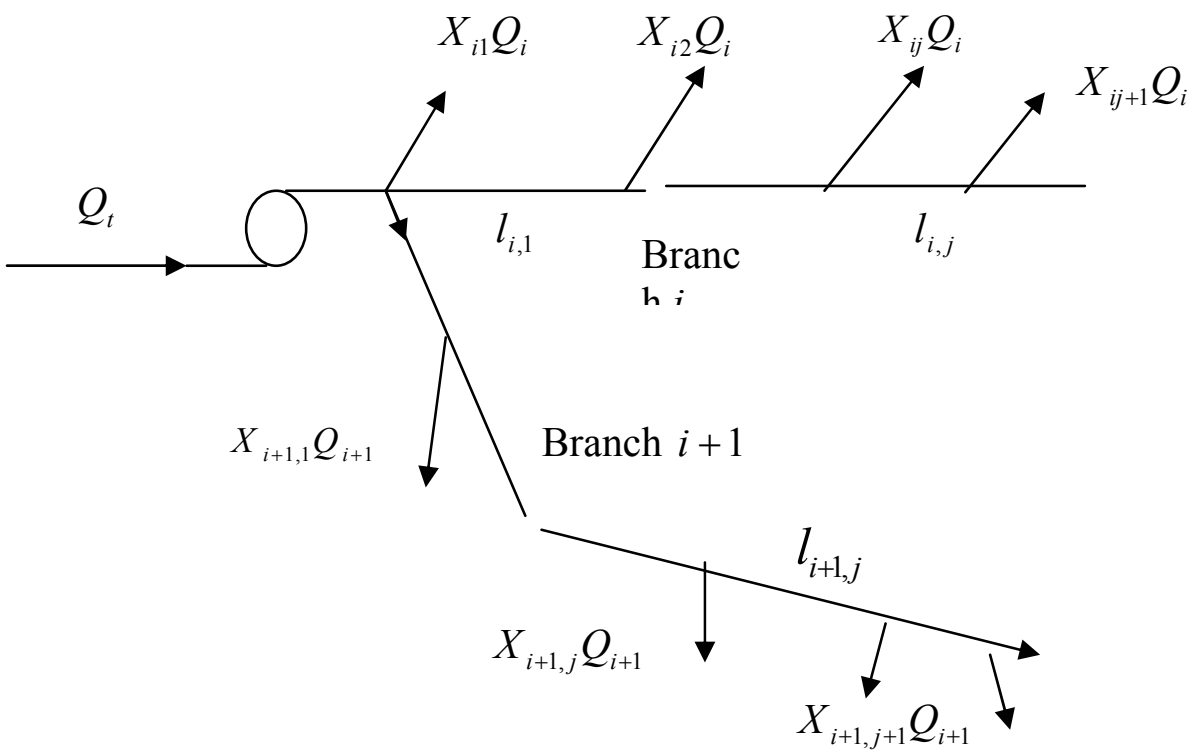

Figure 1. Schematic of a pump-branching pipeline distribution system

\subsection{Pipelines and pump cost}

The cost of pipes is usually related to the diameters and the materials. Cost data in $\mathrm{SR} / \mathrm{m}$ for PVC pipes and galvanized steel pipes have been correlated, based on prices of the local market, to the following form

$$
C_{p}=a D^{b}
$$




$$
\begin{aligned}
& a=10 \quad b=1 \quad \text { for galvanized steel up to 4" dia. } \\
& a=2.36 \quad b=1.09 \quad \text { for PVC pipes }
\end{aligned}
$$

$D$ is the nominal diameter in inches, schedule 40 for steel pipes. Installation of the pipelines adds to the cost of purchasing the pipes, if $C_{m}$ is the installation cost per unit length then, the total piping installation cost is:

$$
\sum_{i=1}^{n} \sum_{j=1}^{m_{i}} C_{m} l_{i j}
$$

Usually the cost of pumps is related to the power of the pump motor, which is a function of the flow rate at maximum system head $H_{f i}$. Making use of Eqs.2 and 3 the cost of the system can be written as,

$$
C_{p p}=\sum_{i=1}^{n} \sum_{j=1}^{m_{i}}\left(a_{i j} D_{i j}^{b}+C_{m}\right) l_{i j}+\alpha_{p}\left[\frac{w Q_{t} H_{f i}}{\eta}\right]
$$

where $\alpha_{p}$ is a constant determined by fitting the available market data on pumps.

\subsection{Operation cost}

The effective part of a network operation cost is the cost of energy consumed for pumping $Q_{t}$ against a system friction and other losses (valves, expansion, contraction, elbows...), $H_{i}$. Noting that $H_{i}$ for all branches is a fixed value (parallel flow pipes). The head loss is;

$$
H_{f i}=Q_{i}^{2} \sum_{j=1}^{m_{i}} \frac{f_{i j} l_{i j}}{G D_{i j}^{5}}\left(1-\sum_{k=1}^{j} X_{i k}\right)^{2}=Q_{i}^{2} Y_{i}
$$

where $Y_{i}$ is a characteristic group for branch $i, G$ is a constant $=2 g(\pi / 4)^{2}$ and $f$ is assumed constant independent on Reynolds number.

For any two parallel pipelines $i$ and $k$ the equal pressure drop condition gives

$$
\frac{Q_{i}}{Q_{k}}=\sqrt{\frac{Y_{k}}{Y_{i}}}
$$

Combining Eqs. 1 and 6 gives the total flow rate $Q_{t}$ passing through the system as:

$$
Q_{t}=Q_{i}+Q_{i} \sqrt{\frac{Y_{i}}{Y_{i+1}}}+Q_{i} \sqrt{\frac{Y_{i}}{Y_{i+2}}}+\ldots
$$


Equation 7 gives a relation to determine the flow at any branch $Q_{i}$ as

$$
\mathrm{Q}_{i}=\mathrm{Q}_{t} /\left[1+\sqrt{\mathrm{Y}_{i}} \sum_{k \neq i}^{n} \frac{1}{\sqrt{Y_{k}}}\right]
$$

The cost of energy consumed over a period of $\tau$ (hours) is

$$
C_{e}=c_{e} \frac{w Q_{t} H_{f i}}{\eta} \tau
$$

where $\mathrm{c}_{e}$ is the specific cost of energy, SR/kWh.

Substituting for $H_{f i}$ and $Q_{i}$ from Eqs.5 and 8 into Eq.9 and adding the fixed cost $C_{p p}$ to that of the energy $C_{e}$ gives the objective function as;

$$
Z=r \sum_{i=1}^{n} \sum_{j=1}^{m}\left(a_{i j} D_{i j}^{b}+C_{m}\right) l_{i j}+\frac{C Q_{t}^{3}}{\left(\sum_{i=1}^{n} \frac{1}{Y_{i}}\right)^{2}}
$$

where $C$ is a parameter depends upon the cost of electricity, annual period of operation (8760 h maximum) and pump efficiency, a fixed value for $C$ is assumed for this analysis, $r$ is the fixed charge rate on money (0.14).

The objective function $Z$ presents the total annual cost, to be minimized for the state variables $D_{i j}$. Therefore;

$$
Z_{\text {min }}=f\left(D_{i j}^{o}\right)
$$

where the superscript ${ }^{\circ}$ denotes optimal value for a pipe segment $i j$. The only constraint for this system is to get diameters within the practical dimensions of pipes, i.e.

$$
D_{\min } \leq D_{i j}^{o} \leq D_{\max }
$$

\section{Scheme of solution}

The least annual cost principle gives the condition for minimum $Z$, as,

$$
\frac{\partial Z}{\partial D_{i j}}=\underline{0}
$$

applying the principle of partial differentiation Eqs.10 and 13 give 


$$
{ }_{i j} \mathrm{~b} \mathrm{D}_{i j}^{b-1}=\frac{5 \mathrm{CQ}_{t}^{3}{ }^{\mathrm{f}}{ }_{i j}}{\mathrm{GD}_{i j}^{6}} \frac{\left[1-\sum_{k=1}^{j} \mathrm{x}_{i k}\right]^{2}}{\mathrm{Y}_{i}^{3 / 2}\left[\sum_{i=1}^{n} \frac{1}{\sqrt{\mathrm{Y}_{i}}}\right]^{3}}
$$

Equation 14 is a set $(i j)$ of a nonlinear-coupled system of equations, solution of that gives the values for $D_{i j}^{o}$. It can be simplified by assuming $b=1$ this gives the ratio between two optimal pipes $D_{i j}^{o}$ to that $D_{k j}^{o}$ at any other branch as;

$$
\left(\frac{D_{i j}^{o}}{D_{k j}^{o}}\right)^{6}=\left(\frac{f_{i j} l_{i j}}{f_{k j} l_{k j}}\right)\left(\frac{K_{k j}}{K_{i j}}\right)\left(\frac{Y_{k}}{Y_{i}}\right)^{3 / 2}\left[\frac{1-\sum_{p=1}^{j} X_{i p}}{1-\sum_{p=1}^{j} X_{k p}}\right]^{2}
$$

where $K_{i j}$ is a constant defined as;

$$
K_{i j}=\frac{a_{i j} G l_{i j}}{5 C Q_{t}^{3}}
$$

\subsection{Consistency of the formulation}

Equation 15 is examined for simple limiting conditions, for the case of closed emitters, i.e. $X_{i j}=0$. Substituting for $Y_{i j}$ Eq. 15 becomes:

$$
D_{k}^{0}=D_{i}^{o}\left[\frac{f_{k} l_{k}}{f_{i} l_{i}}\right]^{1 / 6}\left[\frac{K_{k}}{K_{i}}\right]^{1 / 6}
$$

which is a relation obtained independently in a previous work $[11,1]$.

For a single pipe without drawoffs, $i=j=1$ equation 15 leads to

$$
D^{o}=\left[\frac{f l}{K}\right]^{1 / 6}=\left[\frac{5 C f Q_{t}^{3}}{a G}\right]^{1 / 6}
$$

This result is a well-established relation for a single pipeline [1]. 


\subsection{Solution Procedure}

It is suggested here to minimize Eq.10 in two steps, first by replacing each pipeline with an equivalent one without any emitters and the equivalent optimal diameters can be obtained by solving Eq.17. The solution gives a minimum cost function, $Z_{e}$, for the equivalent system. It is actually the minimum cost of an equivalent network, which combines the pipe cost and energy cost as:

$$
\left.\begin{array}{l}
Z_{e}=a_{i e} D_{i e} l_{i e}+\frac{C f_{i e} l_{i e}}{G D_{i e}^{5}} Q_{t}^{3} \\
Z_{e}=Z_{e 1}+Z_{e 2}
\end{array}\right\}
$$

Splitting the cost equation, Eq.10, into two similar parts the cost of pipes $Z_{I}$ and that of energy $Z_{2}$ then

$$
Z_{e 1}+Z_{e 2}=Z_{1}+Z_{2}
$$

The constant $a_{i e}$ (Eq.19) is a false cost index introduced here to enable extending the equivalent solution to represent the actual network. The value of $a_{i e}$ is assumed and Eq.19 is solved for the equivalent diameter of each branch $D_{i e}^{o}$. Equating $Z_{e 2}$ and $Z_{2}$ gives the diameter of the first segment of each branch $D_{i 1}^{o}$. New value of $a_{i e}$ is then determined by employing $Z_{e l}=Z_{1}$, using the obtained diameters $D_{i 1}^{o}$. Comparing the new $a_{i e}$ 's with the assumed values. If equal or within a reasonable accuracy, the solution is terminated else the new $a_{i e}$ 's are used to determine new values for $D_{i j}^{o}$, and the iteration continues. Once the final $D_{i 1}^{o} \mathrm{~s}$ are determined for each branch, the optimal diameters for the other pipes are calculated from;

$$
D_{i j}^{o}=\left(\frac{a_{i 1}}{a_{i j}}\right)^{1 / 6}\left[1-\sum_{k=1}^{j} X_{i k}\right]^{1 / 3} D_{i 1}
$$

and the flow rate through each branch is determined from Eq.8.

\section{Case Studies}

The first numerical case study is a 3-branch system with 3 draw-off points along each branch. The emitters are located at unequal distances as seen in Table 1.and the extraction ratios are shown in Fig.2: 


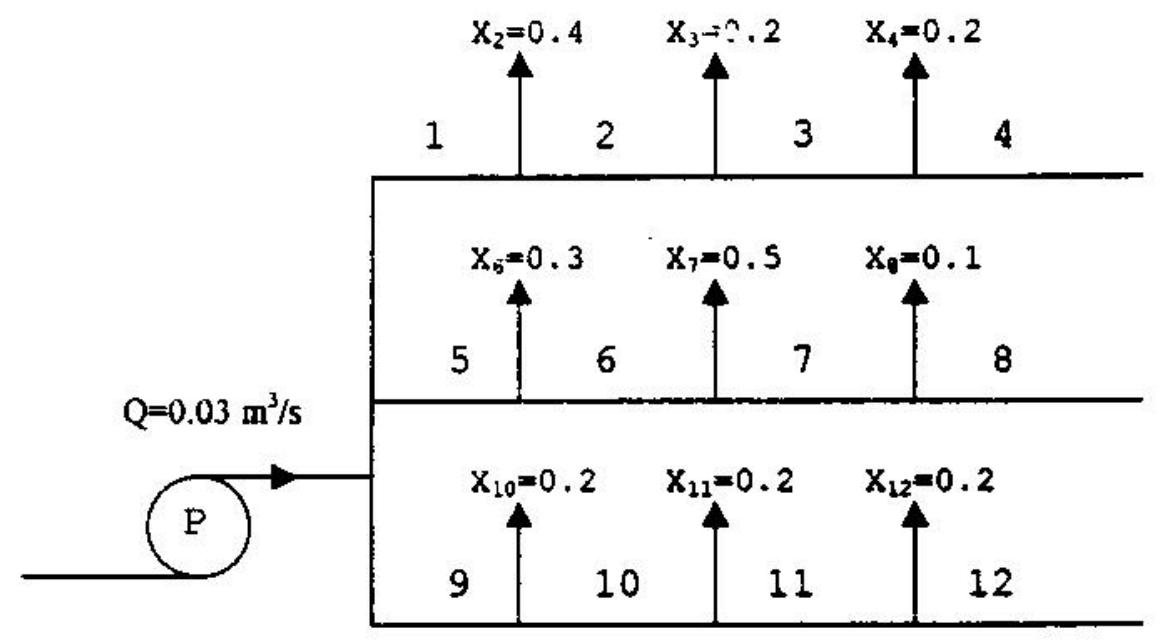

Figure 2: Schematic diagram for case 1.

Table 1. Data for case study No.1

\begin{tabular}{|l|l|l|l|l|l|l|l|l|l|l|l|l|}
\hline Pipe No. & 1 & 2 & 3 & 4 & 5 & 6 & 7 & 8 & 9 & 10 & 11 & 12 \\
\hline Length, m & 50 & 150 & 50 & 100 & 200 & 100 & 50 & 50 & 100 & 100 & 100 & 100 \\
\hline
\end{tabular}

For a total rate of $0.03 \mathrm{~m}^{3} / \mathrm{s}$ the calculated optimum diameters and flow rate within each pipe are given in Table 2. For this example the minimum cost function $Z$ is obtained for a constant friction factor $f=0.02, \mathrm{r}=0.15$ and $c_{e}=$ $.07 \mathrm{SR} / \mathrm{kWh}$.

Table 2. Optimum diameters and flow rates, for case study No. 1

\begin{tabular}{|l|c|c|c|c|c|c|c|c|c|c|c|c|}
\hline Pipe No. & 1 & 2 & 3 & 4 & 5 & 6 & 7 & 8 & 9 & 10 & 11 & 12 \\
\hline $\begin{array}{l}\text { Optimum } \\
\text { diameter, } \mathrm{m}\end{array}$ & 0.11 & 0.093 & .081 & 0.065 & 0.14 & 0.12 & 0.08 & 0.06 & 0.14 & 0.13 & 0.12 & 0.11 \\
\hline $\mathrm{Q}_{i} \times 10^{3} \mathrm{~m}^{3} / \mathrm{s}$ & 7.07 & 4.24 & 2.83 & 1.41 & 11.15 & 7.8 & 2.2 & 1.11 & 11.8 & 9.4 & 7.1 & $4.7^{*}$ \\
\hline
\end{tabular}

* The calculated flow rates add up to $.0302 \mathrm{~m}^{3} / \mathrm{s}$ that presents $0.7 \%$ deviation in the mass balance as rounding off error. 
The second numerical case study considers a portion of the irrigation network at King Abdulaziz University campus, Fig.3, for which all pipelines are PVC, of $0.076 \mathrm{~m}$ diameter. The input flow rate to the system is 0.1505 $\mathrm{m}^{3} / \mathrm{s}$, the system is treated as a two parallel branch system with 13 emitters on each line. The dimensions and the percentage ratio of bleeding for the two branches are given in Table 3 along with the results. The optimum diameters and the flow rate through each segment are presented. The calculated optimum pipe diameter is a guide to select the closest standard pipe size as seen under the standard matching, Table. 3 . This case is just to illustrate the applicability of the analysis and software to handle a system with a large number of drawoff points.

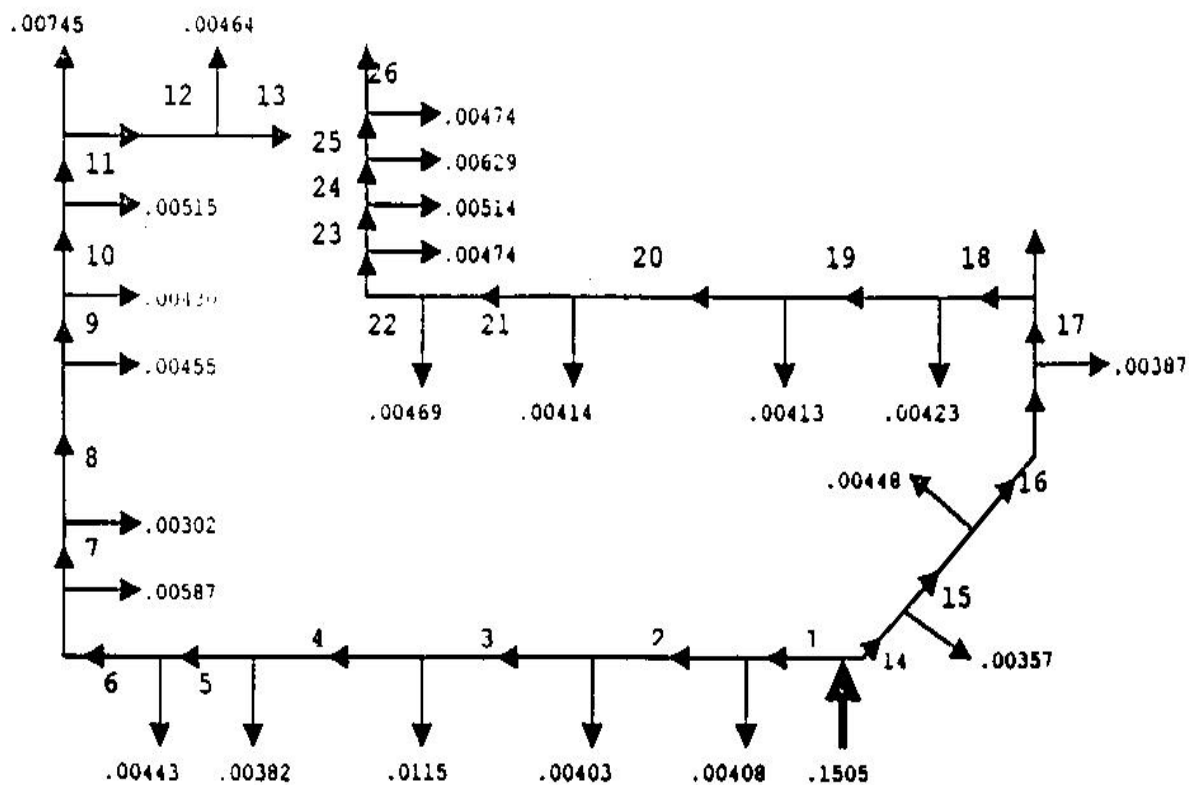

Figure 3: Schematic diagram for case 2.

The third case study considers a single pipeline $5.8 \mathrm{~km}$ long, with large flow rate $1 \mathrm{~m}^{3} / \mathrm{s}$ distributing water at 3 stations, $X=0.3$ at each extraction point, Fig.4. 
Table 3: PVC two parallel lines, portion of KAAU irrigation network

\begin{tabular}{|c|c|c|c|c|c|}
\hline & Pipe No. & $\begin{array}{c}\text { Length } \\
\quad m\end{array}$ & $X$ & $\begin{array}{c}\text { Optimum } \\
D^{o}, m\end{array}$ & $\begin{array}{c}\text { Standard } \\
\text { matching } \\
\text { D }\end{array}$ \\
\hline \multirow{13}{*}{$\begin{array}{l}\overrightarrow{0} \\
z \\
\overline{0} \\
\bar{\Xi} \\
\bar{n}\end{array}$} & 1 & 2 & .06 & .34 & \multirow{5}{*}{$11 / 4 "$} \\
\hline & 2 & 10 & .06 & .33 & \\
\hline & 3 & 19.8 & .18 & .32 & \\
\hline & 4 & 4 & .06 & .30 & \\
\hline & 5 & 9 & .06 & .29 & \\
\hline & 6 & 17.8 & .09 & .28 & \multirow{3}{*}{$11 / 4 "$} \\
\hline & 7 & 2.4 & .05 & .27 & \\
\hline & 8 & 36.8 & .072 & .26 & \\
\hline & 9 & 13.6 & .07 & .24 & \multirow{3}{*}{$1 "$} \\
\hline & 10 & 25.6 & .08 & .23 & \\
\hline & 11 & 4.2 & .118 & .21 & \\
\hline & 12 & 20.8 & .073 & .15 & \multirow{2}{*}{$1 / 2 "$} \\
\hline & 13 & 3.6 & 0.027 & .10 & \\
\hline \multirow{13}{*}{ 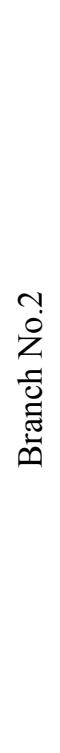 } & 14 & 12 & .04 & .31 & \multirow{4}{*}{$11 / 4 "$} \\
\hline & 15 & 6 & .05 & .31 & \\
\hline & 16 & 30 & .044 & .30 & \\
\hline & 17 & 3 & .4 & .30 & \\
\hline & 18 & 10.4 & .048 & .24 & \multirow{5}{*}{$1 "$} \\
\hline & 19 & 17 & .04 & .23 & \\
\hline & 20 & 6.2 & .05 & .22 & \\
\hline & 21 & 13 & .05 & .21 & \\
\hline & 22 & 20 & .05 & .20 & \\
\hline & 23 & 15 & .06 & .19 & \multirow{3}{*}{$3 / 4 "$} \\
\hline & 24 & 1.2 & .07 & .17 & \\
\hline & 25 & 13.6 & .05 & .14 & \\
\hline & 26 & 8 & 0.048 & .11 & $1 / 2 "$ \\
\hline
\end{tabular}




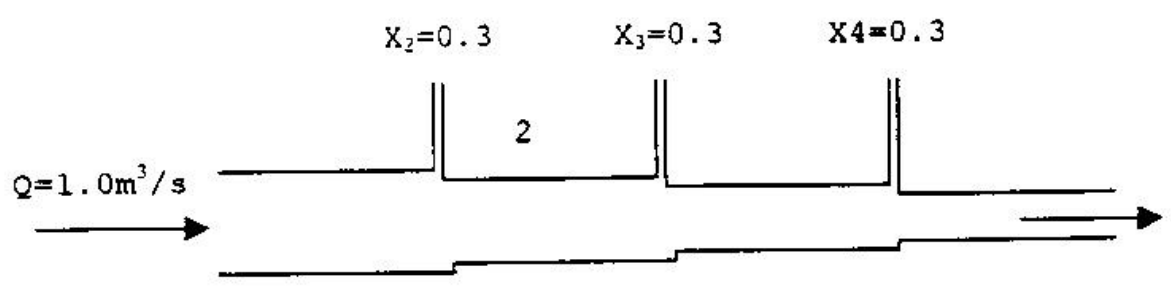

Figure 4: A Single pipeline with three drawoff points.

For this case study the cost index for steel pipes is taken as $400 \mathrm{SR} / \mathrm{m}-\mathrm{m}$, and a constant friction factor $f=0.02$ and 0.14 fixed charge rate. The cost of electricity is variable 0.07 and $0.15 \mathrm{SR} / \mathrm{kWh}$ and for 8000 hours annual working hours, the constant $C$ varies between 1120 to 2186 respectively. The optimum diameters for minimum annual cost are presented in Table 4 . The results in Table 4 show that the increase in the cost of electricity is associated with increase in pipe diameters but the relation is not linear. Doubling the unit cost of electricity increases the annual expenses from 246,182 SR to 275,223 $\mathrm{SR}$, the difference is only $11.8 \%$. The flow average velocity inside each pipe segment is calculated to check that it is not increasing the practical limit of $3 \mathrm{~m} / \mathrm{s}$ for water.

Table 4: Optimum diameters and flow velocities for a single pipeline with three bleeding points

\begin{tabular}{|c|c|c|c|c|c|c|}
\hline \multirow{2}{*}{$\begin{array}{c}\text { Pipe } \\
\text { No. }\end{array}$} & Length & \multirow{2}{*}{$\mathrm{Km}$} & $\mathrm{X}$ & \multicolumn{2}{c|}{$C_{e}=0.07 \mathrm{SR} / \mathrm{kWh}$} & \multicolumn{2}{|c|}{$0.15 \mathrm{SR} / \mathrm{kWh}$} \\
\cline { 4 - 7 } & & $D^{\mathrm{o}} \mathrm{m}$ & $V \mathrm{~m} / \mathrm{s}$ & $D^{\mathrm{o}} \mathrm{m}$ & $V \mathrm{~m} / \mathrm{s}$ \\
\hline 1 & 1.0 & & .73 & 2.4 & .82 & 1.90 \\
2 & 2.5 & .3 & .65 & 2.1 & .73 & 1.69 \\
3 & 1.4 & .3 & .53 & 1.75 & .6 & 1.40 \\
4 & .9 & .3 & .34 & 1.1 & .38 & .88 \\
\hline
\end{tabular}

The presented 3 examples demonstrate the validity and potential of the present analysis. 


\section{Conclusion}

A cost function is developed for a system that comprises a single pumping station and $n$ branching pipeline, with arbitrary draw-off points along each pipeline. The model is based on the cost of piping system, pump and the energy consumed to operate the system. The least annual cost principle is employed to determine the optimal diameters of all piping segments. For minimum annual cost the formulation leads to a set of coupled nonlinear algebraic equations, which are solved iteratively. The starting values for the proposed solution routine are obtained by solving an equivalent piping system without any emitters. The optimal diameters are then corrected to satisfy a cost index parameter that relates both the actual and equivalent systems. The model is employed for a simple 3 parallel pipelines with 12 emitters. A second case study is also presented which considers part of the irrigation network at King Abdulaziz University Campus. A third case is a single $5.8 \mathrm{~km}$ pipeline distributing water at 3 stations.

\section{References}

[1] Nolte, B. C., Optimization pipe size selection., Gulf Publishing Co. Book Division, pp. 7-20, (1979).

[2] Hathoot, M. H., Minimum cost design of horizontal pipelines, Journal of Transportation Eng. 110, 3, 382-389, (1984).

[3] Ferreira, J. and Vidal, R., Optimization of a pump-pipe system by dynamic programming. Engineering optimization, 7, pp 241-251, (1984).

[4] Kabir, J., Optimization design of water transmission mains. in Pipeline Design and Installation, Edited by Kenneth, K. Kienow, published by ASCE, pp 609-618 (1990).

[5] Stephenson, D., Pipelines Design for Water Engineers, in Developments in Water Science, Vol.15, 2nd edition, Elsevier Sci., pp 34-52 (1981).

[6] Kuczera, G., Network Linear Programming Codes for Water-Supply Headworks Modeling, Journal of Water Resources Planning and Management, 119, 3, pp 412-418 (1993).

[7] Cembrowicz, R. G., Ates, S. and Nguyen K. M., Mathematical Optimization of Main Water Distribution System, City of Hanoi, Vietnam, 6th Int. Conf. on Hydraulic Eng. Software. Editor, Blain, W. R. Computational Mechanics Publications, Southampton, pp 163-172 (1996).

[8] Srinivasan, V. S. and Guimaraes, J. A., Criteria for the Economic Design of Sub-unit of a Trickle Irrigation System, , 6th Int. Conf. on Hydraulic Eng. Software. Editor, Blain, W. R. Computational Mechanics Publications, Southampton, pp 173-180 (1996).

[9] Eduardo, A. H. and Marino, M. A., Drip Irrigation Nonlinear Optimization Model. J. Irrig. and Drainage Eng., 116, 4, pp 479-495 (1990). 
[10] Mohtar, R. H., Bralts, V. F. and Shayya, W. H., A Finite Element Model for the Analysis and Optimization of Pipe Networks." Trans. Am. Soci. of Agric. Engrs. 34, 2, pp 393-401 (1991).

[11] Afshar A. and Miguel, A. M., Optimization Models for Wastewater Reuse in Irrigation, J. Irrig. and Drainage Eng., 115, 2, pp 185-202 (1989).

[12] Dandy, G. C., Simpson, A. R., and Murphy, L. J., An improved Genetic Algotithm for Pipe Network Optimization, Water Resources Research, 32, 2, pp 449-458 (1996)

[13] Simpson, A. R., Dandy, G. C., and Murphy L. J., Genetic Algorithm Compared to Other Techniques for Pipe Optimization, J. Water Resources, Planning and Management. Div. American Soc. Civ. Eng., 120, 4, pp 423443 (1994)

\section{Nomenclature}

$a \quad$ cost index for pipes $(\$ / \mathrm{m}-\mathrm{m})$

$b \quad$ exponent for pipe price

$c_{e} \quad$ cost of energy $(\$ / \mathrm{kWh})$

$C_{e} \quad$ annual cost of energy (\$/y)

$C_{o} \quad$ operation cost $(\$ / \mathrm{y})$

$C_{p} \quad$ cost of pipes (\$)

$C_{m} \quad$ cost of pipes installation (\$)

$C_{p p} \quad$ cost of pumps and piping system (\$)

$D$ pipe diameter, $\mathrm{m}$

$f \quad$ friction factor

$g$ gravitational acceleration, $\mathrm{m} / \mathrm{s}^{2}$

$G \quad$ constant $=2 \mathrm{~g}(\pi / 4)^{2}$

$H$ pressure head, m water

$H_{f} \quad$ losses due to friction and pipe fittings

$l \quad$ length of pipe, $\mathrm{m}$

$m$ number of emitters for a single pipeline

$n \quad$ number of parallel pipelines

$P \quad$ pressure $\left(\mathrm{N} / \mathrm{m}^{2}\right)$

$Q \quad$ flow rate $\left(\mathrm{m}^{3} / \mathrm{s}\right)$

$r \quad$ fixed charges rate

$Y$ parameter defined by Eq.5 m/( $\left.\mathrm{m}^{3} / \mathrm{s}\right)^{2}$

$w \quad$ Specific weight, $\mathrm{kg} / \mathrm{m}^{3}$

$Z \quad$ total annual cost (\$/y)

$\begin{array}{lll} & & \text { Subscripts } \\ i & \text { equivalent } & \\ j & \text { integer, pipe number } & \\ o & \text { integer for length between emitters } \\ p & \text { at outlet } & \\ t & \text { pumps } & \\ & \text { total } & \text { Superscripts } \\ o & \text { optimum } & \end{array}$




\title{
تحديد الأفار المثلى لشبكة أنابيب ذات قط توزيع
}

\author{
محمد بدر حبيب اله وجلل محمد زكى \\ كلية الهنهة، جامعة المك عبد العبد العزيز \\ جلة - المملكة العربية للسعولية
}

المستخلص : ققدم هذه الدرلمة دالة للسعر لظعلم مكون من مضخة

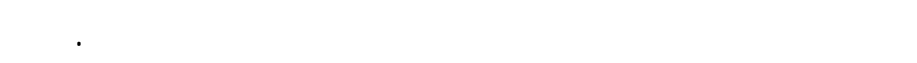

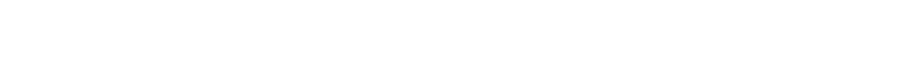

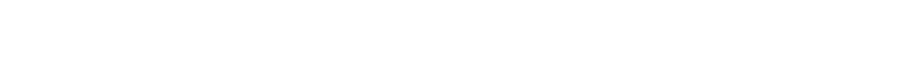

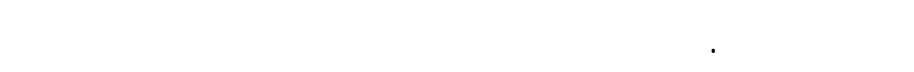

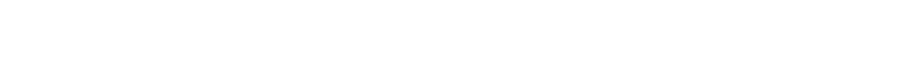

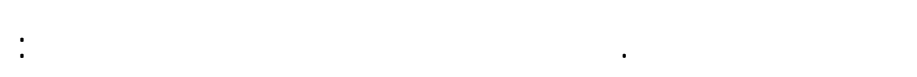

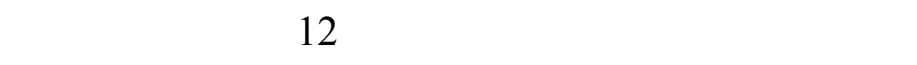

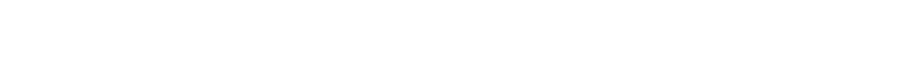

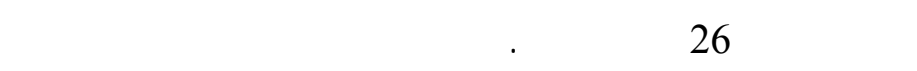

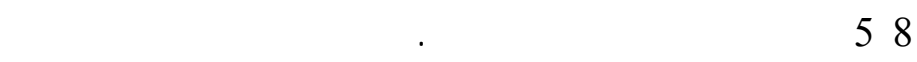
أُطار المولسير الني تعطى التل تكلفةسنوية. 